\title{
Changes in coronary vessel resistance during postischemic reperfusion and effectiveness of nitroglycerin
}

\author{
Gerhard A. Kalweit, MD \\ Jochen D. Schipke, $P h D^{b}$ \\ Erhard Godehardt, $\mathrm{PhD}^{\mathrm{a}}$ \\ Emmeran Gams, MDa
}

From the Department of Thoracic and Cardiovascular Surgery ${ }^{\mathrm{a}}$ and Institute of Experimental Surgery, ${ }^{b}$ Heinrich-HeineUniversity, Düsseldorf, Germany.

Received for publication Aug 23, 2000; revisions requested Nov 29, 2000; revisions received Jan 2, 2001; accepted for publication Feb 12, 2001.

Address for reprints: Gerhard A. Kalweit, MD, Department of Thoracic and Cardiovascular Surgery, Heinrich-HeineUniversity, Moorenstraße 5, D-40225 Düsseldorf, Germany.

J Thorac Cardiovasc Surg 2001;122:1011-8

Copyright (C) 2001 by The American Association for Thoracic Surgery

$0022-5223 / 2001 \$ 35.00+0 \quad \mathbf{1 2 / 1 / 1 1 5 1 5 8}$

doi:10.1067/mtc.2001.115158
Objective: Microvascular incompetence after ischemia and reperfusion may compromise the normal postischemic coronary perfusion and additionally jeopardize the recovery of the myocytes. We investigated whether such a form of acute endothelial dysfunction occurs in the routine operative setting despite the use of protective measures. For this purpose, we measured pressure-flow relations in the coronary vasculature during heart operations before and after ischemia and after reperfusion and their reaction to the nitric oxide donor nitroglycerin.

Methods: Forty-eight patients with a low risk profile scheduled for routine coronary artery bypass surgery were included. During normothermic extracorporeal circulation, the fibrillating heart was completely excluded from bypass by clamping of the ascending aorta and snaring of the caval veins. It was relieved of blood by opening the right atrium and venting the left atrium and ventricle to avoid distention. The coronary vessels were perfused under controlled flow, and the perfusion pressures were monitored. This protocol was performed in 24 patients before and immediately after ischemia and after a reperfusion period.

Results: Compared with the preischemic control, vascular resistance was decreased by $17 \%(P<.003)$ immediately after ischemia but increased again by $46 \%(P<$ $.0001)$ during an average of 25 minutes of reperfusion and, even more important, by $23 \%(P<.028)$ in comparison with the preischemic values. In two groups of 12 patients, nitroglycerin was added to the perfusate either in a dosage of $3 \mu \mathrm{g} \cdot \mathrm{kg}$. $\mathrm{min}^{-1}$ or as a bolus injection of $2 \mathrm{mg}$. Low-dose nitroglycerin did not reduce the elevated postreperfusion resistances significantly, but bolus injection did $(P<.0002)$. Coronary vessel resistance increased during reperfusion in particular in patients with a history of hypertension.

Conclusion: Coronary vasoconstriction during postischemic reperfusion is regularly present in the routine operative setting in cardiac surgery, despite myocardial protection measures. The amount of vasoconstriction varies considerably and is particularly increased in patients with hypertension. The nitric oxide donor nitroglycerin can normalize the elevated resistances, but only in high dosages. This demonstrates a preserved ability of vascular smooth muscle to relax. The phenomenon had no sequelae in our low-risk patients having elective operations. However, it may gain significance in the case of severe left heart hypertrophy and in patients at risk with both a postoperative low-output syndrome and reduced mean arterial pressures during reperfusion. 


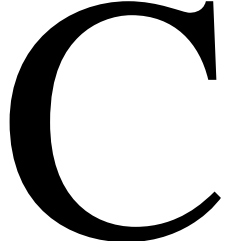
linical efforts in cardiac surgery pertinent to the effects of ischemia and reperfusion concentrate predominantly on myocytes and the contractile function of the heart. Laboratory research has also focused on the endothelium and the microvasculature as targets for injuries during ischemia and reperfusion. ${ }^{1-5}$ Endothelial dysfunction can lead to microvascular incompetence with elevated vascular tone and may in consequence compromise the return of normal postischemic coronary perfusion. ${ }^{6}$ Depending on the amount and time course of the elevated resistance, the recovery of the myocytes will be jeopardized. Because animal models of coronary artery disease cannot easily be transferred to human beings ${ }^{7}$ and ex vivo investigations do not necessarily reflect reality, studies must also be performed under clinical conditions in human beings.

Resistance in the coronary vasculature is influenced by stenosis of the epicardial arteries, wall tension of the myocardium, particularly of the left ventricle, blood viscosity, but most importantly, by the tone of the small arteries. This multitude of factors presents interpretive limitations when changes in coronary vascular resistance are investigated in vivo. Bypass operations, on the other hand, offer a reproducible standard situation with respect to ischemia, reperfusion, and myocardial protection measures. Wall tension of the myocardium and blood viscosity can be kept constant to a wide extent. Stenoses of the epicardial arteries remain unchanged during surgery. Thus, an intraindividual analysis of the vascular reactions to ischemia and reperfusion and of the responses to defined pharmacologic interventions is possible.

The purpose of the present clinical investigation was to examine the response of the human coronary vascular resistance to ischemia and reperfusion when crystalloid cardioplegic solution is used for myocardial protection and to evaluate the effectiveness of the nitric oxide donor nitroglycerin (NTG) in lowering elevated resistances.

\section{Methods \\ Patient Population}

Forty-eight consecutive patients (Table 1) scheduled for elective bypass surgery with a similar pattern of stenosis of the coronary arteries were included in a prospective study. Forty-one of them had triple vessel disease and 7, double vessel disease. The left anterior descending and right coronary arteries were always involved (stenosis $\geq 70 \%$ ), and 6 patients had a main stem stenosis of $50 \%$ to $60 \%$. Aspirin had been discontinued 7 days before the operation. Patients with accompanying valvular disease, an ejection fraction below $30 \%$, unstable angina, myocardial infarction within 4 weeks before the operation, and with emergency operations were excluded from the study. A history of severe or long-lasting hypertension, left ventricular hypertrophy of any other reason, ${ }^{8}$ insulin-dependent diabetes, ${ }^{9}$ main stem stenosis of more than $80 \%$, and occlu- sion of the left anterior descending or right coronary artery and left circumflex coronary artery together were also exclusion criteria, because these factors may influence the coronary resistance independently of the study design. Patients with severe calcifications of the ascending aorta were excluded for technical reasons.

\section{Study Protocol}

A standard protocol of anesthesia was used throughout the operative procedure, consisting of pancuronium and ventilation with enflurane (0.8\%-1.0\% inspired), supplemented with additional doses of fentanyl (0.1-0.2 mg). Extracorporeal circulation (ECC) was instituted by means of bicaval and aortic arch cannulation. The priming volume of the ECC consisted of $2500 \mathrm{~mL}$ of Ringer's solution. If additional volume was needed during ECC, packed red blood cells and Ringer's solution were added to maintain the levels of hemoglobin and hematocrit constantly (hemoglobin $8.4 \pm 0.8 \mathrm{~g} / \mathrm{dL}$, hematocrit $24.8 \% \pm 2.2 \%$ ). Thus, relevant changes in blood viscosity were avoided. Any additional infusions or medications were abandoned. $\mathrm{Po}_{2}, \mathrm{PCO}_{2}$, and $\mathrm{pH}$ in the arterial perfusate were kept constant to avoid effects on vascular tone. Complete cardiac relief during all measurements was achieved by venting the left atrium and ventricle and opening the right atrium while the caval veins were occluded. Thus, wall tension was constantly low. An additional cannula (3.2 mm diameter; Sherwood Medical, Tullamore, Ireland) was inserted into the ascending aorta. This cannula was connected to the cardiotomy reservoir by a separate perfusion line. A small roller pump (Stöckert, Munich, Germany) enabled a flow-controlled perfusion through this line. During the measurements, the ascending aorta was clamped distal to this cannula. Thus, the flow through this cannula represented the blood volume entering the coronary arteries that a competent aortic valve provided. This was ensured by preoperative echocardiography in all patients. In the early phase of the study, we assessed aortic valve competence during data acquisition by intraoperative transesophageal echocardiography. The aortic root pressure, now representing the coronary perfusion pressure, was monitored during the measurements.

Blood samples for evaluation of the metabolic condition of the myocardium was obtained at flow levels of $300 \mathrm{~mL} \cdot \mathrm{min}^{-1}$, that is, 70 to 100 seconds after the onset of reperfusion.

During cardiac arrest, tantamount to the duration of myocardial ischemia, coronary revascularization was performed. Arrest was induced by pressure-controlled administration of $4^{\circ} \mathrm{C}$ cold Bretschneider's cardioplegic solution (F. Köhler Chemie, Bergheim, Germany) given once in a dosage of $25 \mathrm{~mL} / \mathrm{kg}$ body weight at a pressure of $60 \mathrm{~mm} \mathrm{Hg}$. This represented the total amount of cardioplegic solution given. Blood temperature was lowered to $30^{\circ} \mathrm{C}$ during the first 20 minutes of ischemia, and then rewarming was started. Thus, both the arterial blood and the core temperature were normothermic at the onset of myocardial reperfusion. Mean clamping time was $46.4 \pm 7.9$ minutes. During reperfusion, the proximal anastomoses were constructed during aortic side clamping. Mean reperfusion time averaged $25.0 \pm 4.4$ minutes.

The study protocol was approved by the institutional ethics committee, and informed consent was obtained from each patient before the operation. 


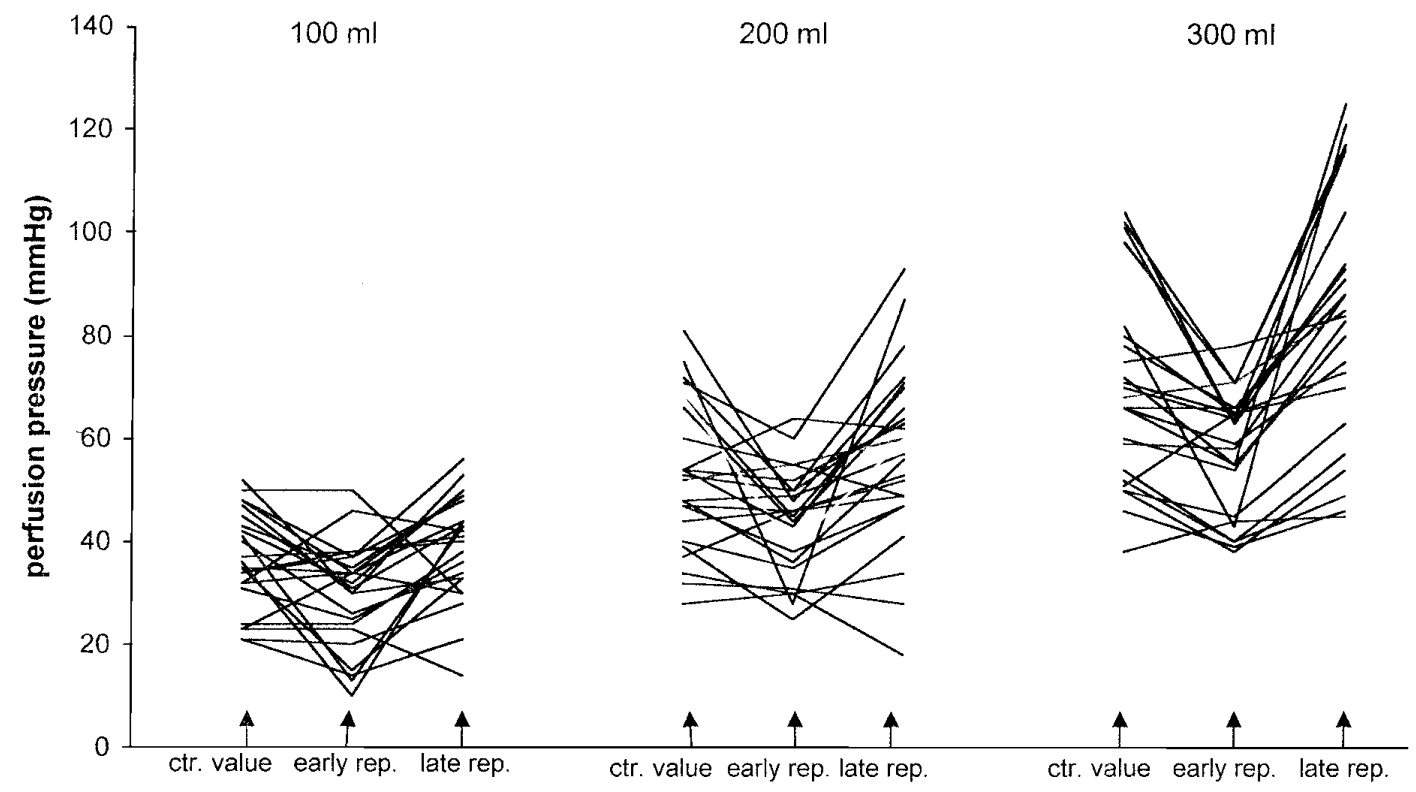

Figure 1. Interaction between pressure and flow at different time points (control value, early reperfusion, and late reperfusion) and for 3 different flow rates $\left(100,200\right.$, and $\left.300 \mathrm{~mL} \cdot \mathrm{min}^{-1}\right)(\mathrm{n}=24)$. At $300 \mathrm{~mL} \cdot \mathrm{min}^{-1}$, coronary resistance decreased significantly at early reperfusion compared with the control value $(P<.003)$, increased until late reperfusion with regard to early reperfusion $(P<.0001)$, and was significantly higher comparing control value and late reperfusion $(P<$.028). ctr value, Control value before ischemia; early rep, early reperfusion immediately after ischemia; late rep, late reperfusion after an average of 25 minutes of reperfusion.

\section{Measurements}

All coronary flow studies were performed with normothermic blood on the completely relaxed and fibrillating heart. In 24 patients the measurements were performed at 3 time points: 10 minutes after the starting of ECC (control value), at the end of ischemia, that is, when cardiac perfusion was reinstituted (early reperfusion), and after an average reperfusion period of 25 minutes (late reperfusion). Perfusion was started with a flow rate of $100 \mathrm{~mL}$ - $\mathrm{min}^{-1}$ and was increased in $100-\mathrm{mL}$ steps up to $300 \mathrm{~mL} \cdot \mathrm{min}^{-1}$. The time needed to obtain constant pressure levels at given flows was 10 to 25 seconds. In 8 patients, the protocol was repeated in decreasing steps to confirm that the pressure levels were reproducible and did not depend on the preceding flow range. The flow protocols were identically repeated at the 3 time points, thus allowing a direct comparison of the results obtained. Measurements with stepwise increases in pump flow were chosen to avoid an acute volume load to the coronary vasculature that might provoke unforeseeable reactions of the small arteries. The already anastomosed bypasses remained clamped at late reperfusion. So that an autoregulatory dilatation of the coronary arteries could be avoided at the time points control value and late reperfusion as a result of complete interruption of flow after clamping of the aorta, blood circulation was maintained by initiating the flow through the additional cannula before the aorta was clamped.

A second series of 24 patients was randomly divided into two groups. In group I the nitric oxide donor NTG was added in a second step to the coronary perfusate during control and late reperfu-
TABLE 1. Demographic characteristics of 48 patients

\begin{tabular}{lc}
\hline Sex (M/F) & $39 / 9$ \\
Age (y) & $67.7 \pm 8.6$ \\
Current smoker & 11 \\
Total cholesterol > $240 \mathrm{mg} / \mathrm{dL}$ & 12 \\
Non-insulin-dependent diabetes & 10 \\
Moderate hypertension & 9 \\
Double vessel disease & 7 \\
Triple vessel disease & 41
\end{tabular}

Data are means $\pm S D$ or number of patients.

sion at a dose of $3 \mu \mathrm{g} \cdot \mathrm{kg} \cdot \mathrm{min}^{-1}$ (normal-dose NTG) while perfusion was maintained at a flow rate of $300 \mathrm{~mL} \cdot \mathrm{min}^{-1}$. In group II the protocol was identical, but the NTG dose applied consisted of a 2-mg bolus (high-dose NTG) injected into the running coronary perfusate.

\section{Statistical Analysis}

For statistical evaluation, the pressures were standardized by subtracting the preischemic values from the ones immediately after ischemia and during reperfusion and by subtracting the values without NTG from the ones with NTG. Thus, the interindividual variability was kept at the smallest possible level. For these differences, a 2-factorial analysis of variance with repeated measure- 
TABLE 2. Coronary perfusion pressures $(\mathrm{mm} \mathrm{Hg})$ at the 3 flow rates before ischemia and standardized pressure differences $(\mathrm{mm} \mathrm{Hg})$ at a flow rate of $300 \mathrm{~mL} \cdot \mathrm{min}^{-1}$

\begin{tabular}{|c|c|c|c|}
\hline Coronary perfusion pressure $(\mathrm{mm} \mathrm{Hg})$ & $100 \mathrm{~mL} \cdot \mathrm{min}^{-1}$ flow & $200 \mathrm{~mL} \cdot \mathrm{min}^{-1}$ flow & $300 \mathrm{~mL} \cdot \mathrm{min}^{-1}$ flow \\
\hline \multicolumn{4}{|l|}{ Time points } \\
\hline 1 & $42 \pm 11$ & $62 \pm 17$ & $77 \pm 20$ \\
\hline II & $35 \pm 13$ & $51 \pm 14$ & $65 \pm 15^{*} \dagger$ \\
\hline III & $44 \pm 10$ & $67 \pm 21$ & $95 \pm 30^{*} \neq \S$ \\
\hline \multicolumn{4}{|c|}{ Standardized pressure differences $(\mathrm{mm} \mathrm{Hg})$ at a flow of $300 \mathrm{~mL} \cdot \mathrm{min}^{-1}$} \\
\hline$I \rightarrow I$ & & & $-12 \pm 14^{*}$ \\
\hline $\mathrm{I} \rightarrow \mathrm{III}$ & & & $18 \pm 15^{*}$ \\
\hline $\mathrm{II} \rightarrow \mathrm{III}$ & & & $30 \pm 20^{*}$ \\
\hline
\end{tabular}

I, Control values before ischemia; II, early reperfusion immediately after ischemia; III, values after a reperfusion period of $24 \pm 5$ minutes. The standard pressure differences were measured in 24 patients without pharmacologic intervention (for further explanation see text). Data are expressed as means \pm SD.

${ }^{*} P$ values indicate significant differences between groups at the flow rate of $300 \mathrm{~mL} \cdot \mathrm{min}^{-1}$.

†I versus II, $P<.003$.

$\ddagger$ versus III, $P<.028$.

§ll versus III, $P<.0001$.

ments was performed with the use of the PROC GLM of the SAS package for statistical analysis (SAS Institute, Inc, Cary, NC), with the one factor being time and the other being flow $(100,200$, or $300 \mathrm{~mL} \cdot \mathrm{min}^{-1}$ ); in the second series, one factor was time and the other was NTG ( $3 \mu \mathrm{g} \cdot \mathrm{kg} \cdot \mathrm{min}^{-1}$ or 2 -mg bolus injection). We chose a model with repeated measurements. Data are expressed as mean and SD.

\section{Results}

In 24 patients, the hemodynamic measurements were performed at the 3 time points described with flow rates of 100 , 200 , and $300 \mathrm{~mL} \cdot \mathrm{min}^{-1}$. Given normal heart weights in all subjects, $300 \mathrm{~mL} \cdot \mathrm{min}^{-1}$ represents a flow range of 0.5 to $0.8 \mathrm{~mL} \cdot \mathrm{g} \cdot \mathrm{min}^{-1}$. Preoperative echocardiographic evaluation showed normal cardiac dimensions in the study cohort, which can be sufficiently correlated to normal heart weight.

As expected, pressures differed significantly during any time of measurement (control value, early reperfusion, and late reperfusion) at the 3 flow rates $(100,200$, and $300 \mathrm{~mL}$. $\min ^{-1}$ ). With regard to the different time points, a significant "time effect" at $300 \mathrm{~mL} \cdot \mathrm{min}^{-1}$ was found comparing the standardized pressures (see "Statistical Analysis") at control value $\rightarrow$ early reperfusion, control value $\rightarrow$ late reperfusion, and early reperfusion $\rightarrow$ late reperfusion; the levels of significance were $P<.003, P<.028$, and $P<.0001$ (Table 2). A significant interaction between the 2 factors (time point and flow) with respect to the vessel resistance was not detected. Figure 1 depicts the course of pressures at the 3 time points for a flow of 100,200 , and $300 \mathrm{~mL} \cdot \mathrm{min}^{-1}$ in 24 patients. It is obvious that only "physiologic" flows of 300 $\mathrm{mL} \cdot \mathrm{min}^{-1}$ give reproducible and comparable results.

In another 12 patients, NTG $\left(3 \mu \mathrm{g} \cdot \mathrm{kg} \cdot \mathrm{min}^{-1}\right.$, normaldose NTG) was added in a second step to the perfusate at the time points control value and late reperfusion during measurement with a flow rate of $300 \mathrm{~mL} \cdot \mathrm{min}^{-1}$. A minimal pressure reduction took place at both time points, in particular at late reperfusion (Figure 2), which was not statistically significant. In another 12 patients, an NTG bolus injection of $2 \mathrm{mg}$ (high-dose NTG) was applied at the time points control value and late reperfusion. Significant reductions of perfusion pressures resulted $(P<.05$ at control value and $P$ $<.0002$ at late reperfusion). The levels at late reperfusion reached the control levels without NTG or went below the control levels (Figure 3).

A repeat retrospective assessment of the stenosis pattern in the coronary angiograms did not demonstrate any correlation between the cumulative degree of stenosis in all diseased vessels and behavior of the resistance.

Relevant metabolic influences on the measurements at control value and late reperfusion caused by $\mathrm{PO}_{2}, \mathrm{PCO}_{2}, \mathrm{pH}$, and lactate levels in the perfusate could be excluded (Table $3)$. The lactate levels in the coronary sinus blood showed an increase above the arterial level at the beginning of reperfusion, reflecting the ischemia-induced acceleration of anaerobic glycolysis. Return to lactate extraction at late reperfusion demonstrated the reconsolidation of mitochondrial oxidative phosphorylation.

\section{Discussion}

To the best of our knowledge, this study shows for the first time in patients undergoing cardiac surgery the development of an increasing hypercontraction of the coronary vasculature during postischemic reperfusion, strongly resembling the phenomenon of "vascular stunning." The significant increase of coronary resistances was demonstrated by means of a standardized protocol. It occurred despite 


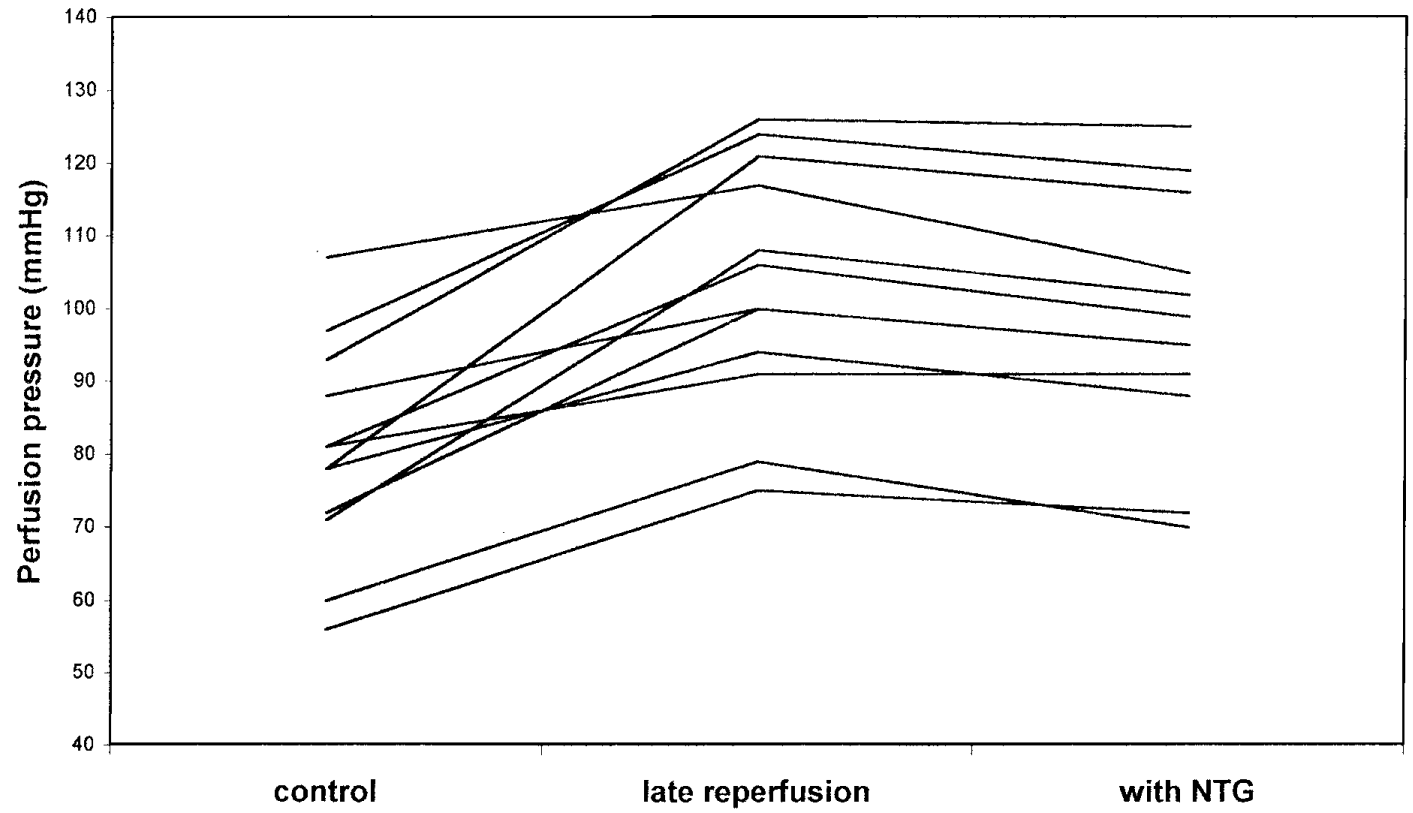

Figure 2. Perfusion pressures in 12 patients at 2 time points (control value and late reperfusion) without nitroglycerin and effect of $3 \mu \mathrm{g} \cdot \mathrm{kg} \cdot \mathrm{min}^{-1}$ nitroglycerin on elevated pressures during late reperfusion, demonstrating minimal changes (not significant). control, Control value before ischemia; late reperfusion, values after a reperfusion period of $24 \pm 5$ minutes; NTG, nitroglycerin.

myocardial protection via effective cardioplegia. A rise was present in all patients but varied considerably, although the study population was rather homogeneous with respect to cardiac and vascular state.

Addition of the endothelium-independent agent NTG to the coronary perfusate in otherwise systemically applicable doses had only minimal influence on the increased resistances, but bolus application abolished it completely, indicating a preserved ability of vascular smooth muscle to relax.

\section{Critique of Methods}

Global coronary resistance is not routinely measured in human beings. Some pitfalls must be excluded to obtain reliable results:

1. The vascular resistance depends on the intramural wall tension. Thus, all measurements were performed on unloaded and nonworking hearts to ensure a tension level as low and constant as possible.

2. The viscosity of the perfusate was maintained by the use of blood with a constant hematocrit value.

3. Coronary flow will clearly depend on heart weight. Major influence resulting from different heart weights was minimized by excluding patients with ventricular hypertrophy. Nevertheless, one portion of the large variation in resistances might contribute to the lack of standardizing coronary flows because of differences in heart weight, which depend on the body weight.
4. Other factors contributing to the considerable variance in the results are both the modified vasodilatory capacity in atherosclerotic coronary arteries ${ }^{10,11}$ and the varying severity of stenoses in the coronary vasculature. To exclude a major effect of the latter factor, we included only patients with a comparable stenosis pattern.

5. Another factor is the dependency of myocardial protection on imbalances of cardioplegic distribution due to coronary stenosis and locally different coronary vessel tone.

6. So that metabolically induced effects on the vascular tone could be excluded, the perfusate was in like manner oxygenated throughout the protocol.

7. Time-dependent factors are negligible because duration of both ischemia and reperfusion was kept within a narrow interval.

8. A nonphysiologic method, measurements on a fibrillating heart, had to be chosen because intraoperative measurements on a beating heart proved to be very time consuming to reach a steady state. They were abandoned because of ethical reasons.

From a clinical point of view, the study had no influence on outcome. The postoperative course of all patients was uncomplicated, with only 18 patients requiring modest dobutamine administration for a maximum of 24 hours postoperatively. Before and during measurements, no catecholamines were given. 


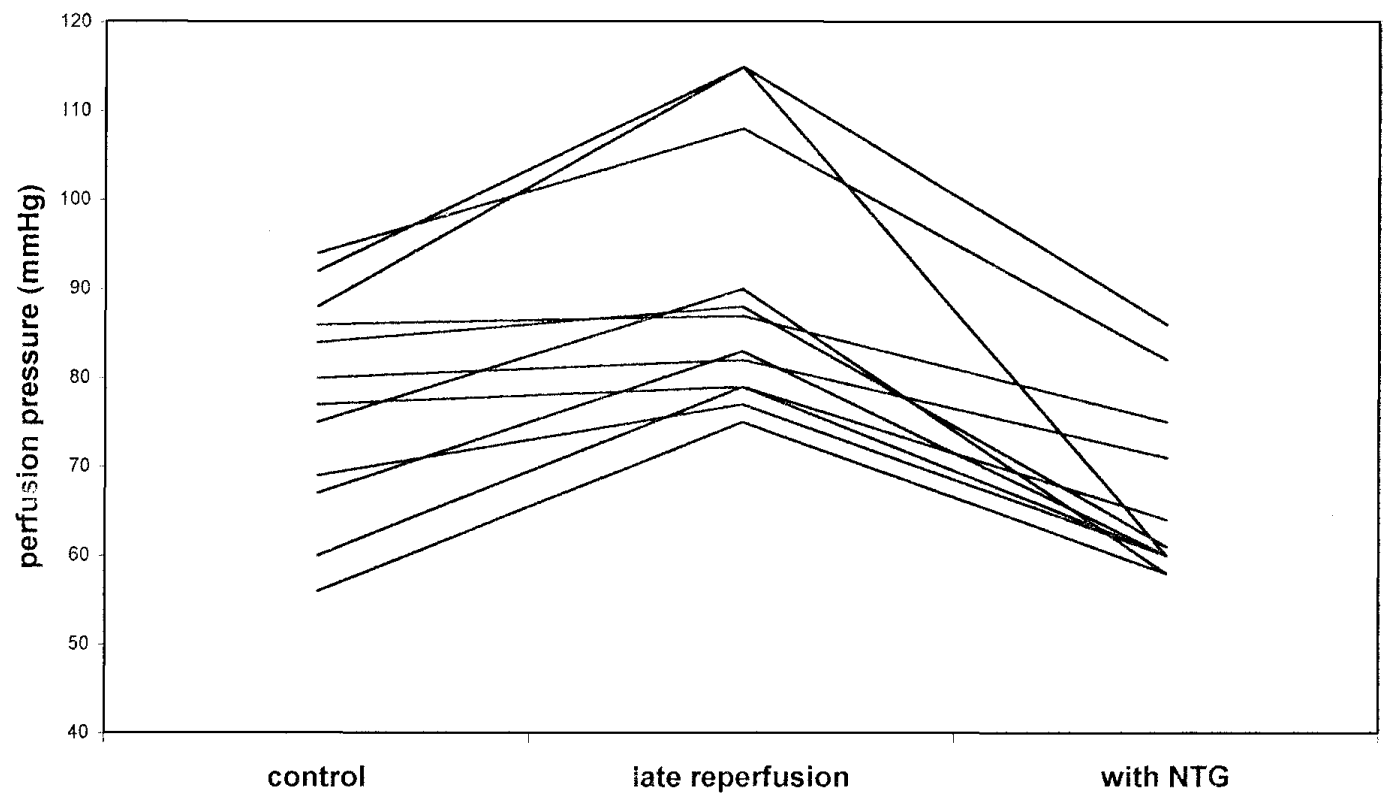

Figure 3. Perfusion pressures in 12 patients at 2 time points (control value and late reperfusion) without nitroglycerin and effect of a 2-mg bolus of nitroglycerin on elevated pressures during late reperfusion, demonstrating a significant decrease in resistances $(P<.0002)$. control, Control value before ischemia; late reperfusion, values after a reperfusion period of $24 \pm 5$ minutes; NTG, nitroglycerin.

\section{Vascular Hypercontraction}

The ventricular function remains depressed after ischemia during reperfusion (myocardial stunning). ${ }^{12}$ The current opinion in basic research defines stunning in a broader sense, not only encompassing contractile function. Thus, terms like metabolic stunning ${ }^{13}$ and vascular stunning ${ }^{14}$ were coined. A variety of factors are blamed for this phenomenon, a prominent one being the endothelium. ${ }^{4,15}$ In a number of in vitro and in vivo animal experiments, the coronary flow reserve was decreased during reperfusion as a consequence of a hypercontractile vasculature. In canine hearts that were subjected to 90 minutes of ischemia, the flow reserve was decreased during 1 week. ${ }^{5}$ Elevated endothelium-dependent hypoxic factors indicating endothelial injury can persist for up to 12 weeks. ${ }^{16}$ Endothelial dysfunction leads to impaired coronary vasorelaxation as early as 2.5 minutes after the onset of reperfusion and aggravates the condition during the next 20 minutes. ${ }^{17}$ To avoid such time-dependent changes in this study, we performed the measurements 20 to $30 \mathrm{~min}$ utes after the onset of reperfusion. Any damage to the endothelial surface could be excluded by scanning electron microscopy, ${ }^{16}$ and it was shown that the postischemic endothelial dysfunction seems to particularly affect the intramyocardial resistance vessels, ${ }^{18}$ although in another study no significant differences between epicardial and endocardial microvascular responses to endotheliumdependent agents were seen. ${ }^{19}$
On the other hand, more mechanistic factors may also play a role, such as microvascular compression caused by both increased cross-sectional area of sarcomeres and intracellular edema. ${ }^{20}$ Other discussed factors are activated coagulation, ${ }^{21,22}$ complement activation, ${ }^{23}$ induction of leukocyte adhesion molecules, ${ }^{24-26}$ and procoagulant factors. ${ }^{27}$ Furthermore, the increased release of vasoconstrictive agents $^{28,29}$ and the decreased release of nitric oxide ${ }^{4,30}$ are discussed.

In contrast to most of the aforementioned experiments, the present study had to consider cardioplegia for myocardial protection. In rats, use of cardioplegic solutions permitted vascular stunning only after prolonged periods of ischemia, longer than those required to observe contractile dysfunction. ${ }^{31}$ Our study aimed at the question of whether the reactions of the vasculature to ischemia and reperfusion known from animal experiments are similar in human beings despite the use of standardized measures of myocardial protection. The protection conferred via cardioplegia in our human study was not complete, because vascular resistance (coronary vascular hypercontraction) was markedly increased. The measurements at lower flows (100 and 200 $\mathrm{mL} \cdot \mathrm{min}^{-1}$ ) showing only minor changes in resistances demonstrate that vascular hypercontraction is indeed the causal factor, because elevated wall tension or external pressure by cellular edema would be even more important at lower flows. A vasomotor response similar to our human findings was obtained in a pig model. ${ }^{32}$ 
TABLE 3. $\mathrm{Po}_{2}, \mathrm{Pco}_{2}, \mathrm{pH}$, and lactate concentration in the blood of the aortic root (AR) and in the coronary venous effluent (CVE) at the 3 time points (I, II, and III) of measurement

\begin{tabular}{|c|c|c|c|c|c|c|c|c|}
\hline & \multicolumn{2}{|c|}{$\mathrm{Po}_{2}(\mathrm{~mm} \mathrm{Hg})$} & \multicolumn{2}{|c|}{$\mathrm{PcO}_{2}(\mathrm{~mm} \mathrm{Hg})$} & \multicolumn{2}{|c|}{$\mathrm{pH}$} & \multicolumn{2}{|c|}{ Lactate (mmol/L) } \\
\hline & AR & CVE & $\mathbf{A R}$ & CVE & AR & CVE & AR & CVE \\
\hline 1 & $248 \pm 38$ & $41 \pm 9$ & $38 \pm 6$ & $47 \pm 7$ & $7.38 \pm 0.07$ & $7.33 \pm 0.05$ & $4.95 \pm 1.5$ & $4.66 \pm 0.9$ \\
\hline ॥ & $229 \pm 35$ & $61 \pm 9$ & $39 \pm 7$ & $48 \pm 5$ & $7.37 \pm 0.07$ & $7.17 \pm 0.11$ & $3.5 \pm 0.9$ & $4.0 \pm 1.0$ \\
\hline III & $218 \pm 34$ & $37 \pm 6$ & $38 \pm 4$ & $46 \pm 5$ & $7.38 \pm 0.05$ & $7.33 \pm 0.06$ & $3.3 \pm 0.5$ & $3.15 \pm 0.6$ \\
\hline
\end{tabular}

Data are means \pm SD. I, Control values before ischemia; II, early reperfusion immediately after ischemia (see text); III, after a reperfusion period of $24 \pm 5$ minutes.

\section{Clinical Relevance}

Only patients with a low risk profile were included to avoid unnecessary complications during the protocol and to exclude factors that might have additional effects on the results. In these patients, the coronary resistance was increased during early reperfusion, thus impeding coronary inflow (ie, oxygen supply). Animal experiments have clearly demonstrated that the reduced oxygen supply additionally jeopardizes the already impaired ventricular function. ${ }^{33}$ Thus, the possibility that a widely used agent like NTG might have an effect on this vasoconstriction is of major interest. With systemically applicable dosages, only a slight decrease in coronary vascular resistance occurred before ischemia-reperfusion, that is, during control investigation. When reperfusion after ischemic cardiac arrest had led to elevated resistances, normal-dose NTG had the same minimal influence on it, but bolus injection proved that the vascular smooth musculature was still able to relax. The above changes in coronary vascular resistances took place despite use of crystalloid cardioplegia for cardiac protection.

In patients with a more complex risk profile, including severe hypertension, diabetes, hyperlipidemia, heavy smoking, and markedly impaired ventricular function, an increasing microvascular incompetence during reperfusion will likely play a more crucial role. ${ }^{34}$ In turn, the coincidence of a number of risk factors like myocardial hypertrophy, prolonged preceding ischemia, and myopathies in combination with an impaired postischemic coronary perfusion may lead to self-promoting heart failure that might even be fatal.

It would be helpful to identify high-risk patients before surgery so that appropriate measures could be taken. Because the impaired vasorelaxation seems to be endothelium dependent, ${ }^{17,18}$ lowering the vascular tone via endothelium-independent agents should be advantageous but is not feasible with normal-dose NTG. The dosages needed cannot be applied systemically.

\section{Mild Hypertension}

The coronary resistances after the 25-minute reperfusion period were elevated to a greater degree in 9 patients than in the remaining 39 patients of the study group. Reanalysis of the risk profiles showed that these 9 patients all had a longer history of mild hypertension that was, however, not yet associated with left ventricular hypertrophy. Hypertension not only promotes the development of atherosclerosis but also leads to the disruption of normal endothelial function. ${ }^{34-36}$ The elevated resistances could be due to a higher wall tension or to a more impaired endothelium-dependent relaxation. The pattern of stenoses in the epicardial coronary arteries cannot explain the different resistances because they were almost identical in all patients. On the other hand, the resistances during early reperfusion were markedly decreased in these patients, demonstrating an excellent dilatory reserve. In consequence, the results from this subgroup with an otherwise relatively low risk profile suggest that attention must be paid in patients with known hypertension to secure adequate coronary inflow during reperfusion. Not only a sufficient cardiac output, but also an adequate pressure level will be important.

\section{Conclusions}

The findings from animal experiments can be transferred to the human coronary vasculature, that is, the coronary resistance in patients with open chest surgery rises after ischemia during early reperfusion. Such "vascular hypercontraction" happened although the heart was protected with cardioplegic solution. Similar studies performed with other forms of cardiac protection are necessary to rule out the weight of the cardioplegia technique on coronary resistances. In routine surgery on patients with a low risk profile, the microvascular incompetence after ischemia/reperfusion does not impair the functional recovery. However, the reduced oxygen supply will likely gain significance in patients with a more complex risk profile.

We are indebted to J. Kunert for his help in statistical evaluation. We thank M. Hoffmann for his assistance in the preparation of the manuscript.

\section{References}

1. Hearse DJ, Maxwell L, Saldanha C, Gavin JB. The myocardial vasculature during ischemia and reperfusion: a target for injury and protection. J Mol Cell Cardiol. 1993;25:759-800. 
2. Lüscher TF, Tanner FC, Tschudi MR, Noll G. Endothelial dysfunction in coronary artery disease. Annu Rev Med. 1993;44:395-418.

3. Seccombe JF, Schaff HV. Coronary artery endothelial function after myocardial ischemia and reperfusion. Ann Thorac Surg. 1995;60:778-88.

4. Sellke FW. Vascular changes after cardiopulmonary bypass and ischemic arrest: roles of nitric oxide synthase and cyclooxygenase. Braz J Med Biol Res. 1999;32:1345-52.

5. Vanhaecke J, Flameng W, Borgers M, Jang IK, Van de Werf F, De Geest $\mathrm{H}$. Evidence for decreased coronary flow reserve in viable postischemic myocardium. Circ Res. 1990;67:1201-10.

6. Verrier ED, Morgan EN. Endothelial response to cardiopulmonary bypass surgery. Ann Thorac Surg. 1998;66:17-9.

7. Schwartz SM, deBlois D, O'Brien ERM. The intima: soil for atherosclerosis and restenosis. Circ Res. 1995;77:445-65.

8. Lamb HJ, Beyerbracht HP, van der Laarse A, Stoel BC, Doornbos J, van der Wall EE, et al. Diastolic dysfunction in hypertensive heart disease is associated with altered myocardial metabolism. Circulation. 1999;99:2261-7.

9. Timimi FK, Ting HH, Haley EA, Roddy MA, Ganz P, Creager MA. Vitamin $\mathrm{C}$ improves endothelium-dependent vasodilation in patients with insulin-dependent diabetes mellitus. J Am Coll Cardiol. 1998;31:552-7.

10. Lüscher TF. Endothelial dysfunction as a therapeutic target. The ENCORE trials. Eur Heart J Suppl. 2000;1(Suppl D):20-5.

11. Quyyumi AA, Dakak N, Mulcahy D, Andrews NP, Husain S, Panza JA, et al. Nitric oxide activity in the atherosclerotic human coronary circulation. J Am Coll Cardiol. 1997;29:308-17.

12. Heyndrickx GR, Millard RW, McRitchie RJ, Maroko PR, Vatner SF. Regional myocardial functional and electrophysiological alterations after brief coronary artery occlusion in conscious dogs. J Clin Invest. 1975;56:978-85.

13. Schipke JD, Sunderdiek U, Korbmacher B, Schwanke U, Arnold G. Utilization of oxygen by the contractile apparatus is disturbed during reperfusion of post-ischemic myocardium. Heart. 1995;16:1476-81.

14. Bolli R, Triana JF, Jeroudi MO. Prolonged impairment of coronary vasodilation after reversible ischemia: evidence for microvascular stunning. Circ Res. 1990;67:332-43.

15. Sellke FW, Friedman M, Dai HB, Shafique T, Schoen FJ, Weintraub RM, et al. Mechanisms causing coronary microvascular dysfunction following crystalloid cardioplegia and reperfusion. Cardiovasc Res. 1993;27:1925-32.

16. Pearson PJ, Lin PJ, Schaff HV, Vanhoutte PM. Augmented endothelium-dependent constriction to hypoxia early and late following reperfusion of the canine coronary artery. Clin Exp Pharmacol Physiol. 1996;23:634-41.

17. Tsao PS, Aoki N, Lefer DJ, Johnson G, Lefer AM. Time course of endothelial dysfunction and myocardial injury during myocardial ischemia and reperfusion in the cat. Circulation. 1990;82:1402-12.

18. Dignan RJ, Kadletz M, Dyke CM, Lutz HA, Yeh T Jr, Wechsler AS. Microvascular dysfunction after myocardial ischemia. $J$ Thorac Cardiovasc Surg. 1995; 109:892-7.

19. Piana RN, Shafique T, Dai HB, Sellke FW. Epicardial and endocardial coronary microvascular responses: effects of ischemia-reperfusion. $J$ Cardiovasc Pharmacol. 1994;23:539-46.
20. Manciet LH, Poole DC, McDonagh PF, Copeland JG, MathieuCostello O. Microvascular compression during myocardial ischemia mechanistic basis for no-reflow phenomenon. Am $J$ Physiol. 1994;266(4 Pt 2):1541-50.

21. Spiess BD. Ischemia-a coagulation problem? J Cardiovasc Pharmacol. 1996;27(Suppl 1):38-41.

22. Valen $\mathrm{G}$. The search for markers of endothelial injury during open heart surgery. Eur J Cardiothorac Surg. 1996;10:297-8.

23. Tofukuji M, Stahl GL, Agah A, Metais C, Simons M, Sellke FW. AntiC5A monoclonal antibody reduces cardiopulmonary bypass and cardioplegia-induced coronary endothelial dysfunction. J Thorac Cardiovasc Surg. 1998;116:1060-8.

24. Edmunds LH Jr. Inflammatory response to cardiopulmonary bypass. Ann Thorac Surg. 1998;66:12-6.

25. Woodman OL, Hart JL, Sobey CG. Prevention of ischaemiainduced coronary vascular dysfunction. Int $J$ Cardiol. 1997;62(Suppl 2):1-99.

26. Kadletz M, Dignan RJ, Loesser KE, Hess ML, Wechsler AS. Ischemia and activated neutrophils alter coronary microvascular but not epicardial coronary artery reactivity. $J$ Thorac Cardiovasc Surg. 1994;108:648-57.

27. Boyle EM Jr, Verrier ED, Spiess BD. Endothelial cell injury in cardiovascular surgery: the procoagulant response. Ann Thorac Surg. 1996;62:1549-57.

28. Lin PJ, Chang CH, Lee YS, Chou YY, Chu JJ, Chang JP, et al. Acute endothelial reperfusion injury after coronary artery bypass grafting. Ann Thorac Surg. 1994;58:782-8.

29. Boyle EM, Pohlman TH, Cornejo CJ, Verrier ED. Endothelial cell injury in cardiovascular surgery: ischemia-reperfusion. Ann Thorac Surg. 1996;62:1868-75.

30. Engelman DT, Watanabe M, Maulik N, Cordis GA, Engelman R, Rousou JA, et al. L-Arginine reduces endothelial inflammation and myocardial stunning during ischemia/reperfusion. Ann Thorac Surg. 1995;60:1275-81.

31. Argano V, Galiñanes M, Edmondson S, Hearse DJ. Effects of cardioplegia on vascular function and the "no-reflow" phenomenon after ischemia and reperfusion: studies in the isolated blood-perfused rat heart. J Thorac Cardiovasc Surg. 1996;111:432-42.

32. Mizuno A, Baretti R, Buckberg GD, Young HH, Vinten-Johansen J, Ma XL, et al. Endothelial stunning and myocyte recovery after reperfusion of jeopardized muscle: a role of L-argine blood cardioplegia. $J$ Thorac Cardiovasc Surg. 1997;113:379-89.

33. Boyle EM, Lille ST, Allaire E, Clowes AW, Verrier ED. Endothelial cell injury in cardiovascular surgery: atherosclerosis. Ann Thorac Surg. 1997;63:885-94.

34. Mulvany MJ. The Seventh Heymans Memorial Lecture Ghent, February 18, 1995. Physiological aspects of small arteries. Arch Int Pharmacodyn Ther. 1996;331:1-31.

35. Schiffrin EL. The endothelium of resistance arteries: physiology and role in hypertension. Prostaglandins Leukot Essent Fatty Acids. 1996;54:17-25.

36. Ambrosio G, Weisman HF, Mannisi JA, Becker LC. Progressive impairment of regional myocardial perfusion after initial restoration of postischemic blood flow. Circulation. 1989;80:1846-61. 